\title{
Stress tensor computations at Mount St. Helens (1995-1998)
}

\author{
Carla Musumeci ( $\left.{ }^{1}\right)$, Stephen D. Malone $\left({ }^{2}\right)$, Elisabetta Giampiccolo $\left({ }^{1}\right)$ and Stefano Gresta $\left({ }^{1}\right)$ \\ (') Dipartimento di Scienze Geologiche, Università di Catania, Italy \\ (2) University of Washington, Geophysics Program, Seattle, WA, U.S.A.
}

\begin{abstract}
Fault plane solutions of 459 events occurring between 1995 and 1998 at Mount St. Helens (State of Washington, Northwest U.S.A.) were considered in order to infer the state of stress beneath the volcano. These events occurred in two distinct depth zones. The shallower zone is between 2 and $5.5 \mathrm{~km}$, with shocks clustering in a tight cylindrical distribution about $1 \mathrm{~km}$ in radius directly beneath the crater. The deeper events are spread over a larger volume from 5.5 to $10 \mathrm{~km}$ depth and surround an aseismic zone below and slightly west of the lava dome. Faulting is characterized by a mixture of strike-slip, reverse and normal faults with maximum compression axes which do not cluster around a single direction. In the deep zone, between 5.5 and $10 \mathrm{~km}, P$ axes define a wheelspoke pattern pointing radially away from the center of the aseismic zone. The 459 fault plane solutions were inverted for stress tensor parameters using the algorithm of Gephart and Forsyth. The inversion of the whole data set revealed that faulting was not produced by a uniform stress distribution. The subdivision of the zone into smaller volumes significantly reduced misfit and contidence areas of the solutions, whereas temporal subdivision of the sample did not lead to significant improvements in terms of stress uniformity. We suggest that the inhomogeneous stress field is consistent with a varying pressure source originating from the inferred crustal magma chamber and a thin conduit extending above it.
\end{abstract}

Key words Mount St. Helens (U.S.A.)-fault-plane solutions - inversion - stress field

\section{Introduction}

Mount St. Helens is the most active volcano in the Cascade Range (fig. 1a). It is located at a small right-stepping off-set of the so-called St. Helens seismic zone (SHZ), a 100-km-long zone of earthquake activity extending to the north and south of the volcano (Weaver et al., 1987). Its most recent series of eruptions began in 1980 when a large landslide and powerful explosive eruption created a large crater following almost 2 months of intense shallow seismicity and in-

Mailing address: Dr. Carla Musumeci, Dipartimento di Scienze Geologiche, Università di Catania, Corso Italia 55 , 95129 Catania, Italy; e-mail: musumeci@mbox.unict.it termittent phreatic eruptions. This eruptive period ended 6 years later, after more than a dozen episodic extrusions of lava built a dome in the crater. After the last eruption (October 21, 1986) the level of earthquake activity was quite low for two years. Since 1988 it has had increased periods of activity from time to time (19891991, 1995, 1998) with low-magnitude events located close to the crater area and at depths shallower than $10 \mathrm{~km}$. However no eruption of magma has occurred. Figure 2 reports the time evolution of foci during the period 1980-1998. Looking at the daily occurrence of the events (fig. 3) in the years following the last eruption, we note that among the three earthquake resumptions (1989-1991, 1995, 1998), the last one was the most intense (more than 700 events in the time span May-July 1998).

Previous studies on the stress state at Mount St. Helens were carried out by Barker and 


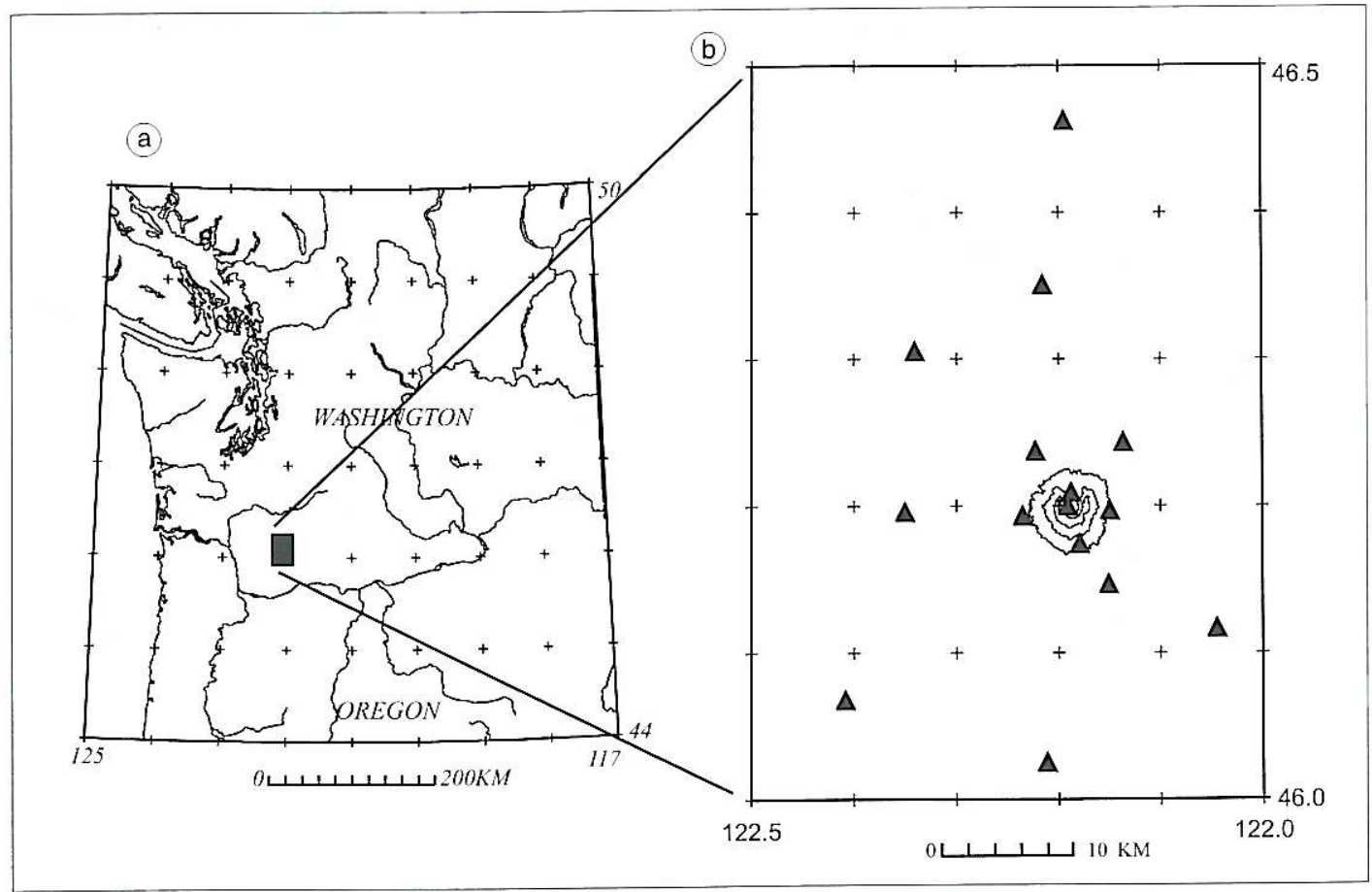

Fig. 1a,b. a) Map of the Mount St. Helens target area; b) triangles show the locations of the 15 closest seismic recording stations of PNSN.

Malone (1991) and Moran (1994) who analyzed the earthquakes occurred in the area after the eruption of May 1980 and in the period 1987 1992, respectively. Focal mechanisms for postMay 18, 1980, and 1987-1992 earthquakes reveal a magmatic system that is evolving with time. The post-May 18, 1980, earthquakes define an aseismic zone between 7 and $11 \mathrm{~km}$, and modeling of $P$ and $T$ axes derived from these events suggest that they occurred in response to a pressure drop in a magma chamber located within the aseismic zone. The 1987-1992 earthquakes define an aseismic zone between 6.5 and $10 \mathrm{~km}$, and modeling suggests that these events are occurring in response to a pressure increase in a magma chamber within this aseismic zone. The two aseismic zones overlap somewhat, but it is unclear from modeling whether or not the magma chamber migrated in 6 years between these two time periods (Moran, 1994).
In the present work, we begin our analysis in 1995 when, after a period of about three years of minor, primarily shallow seismicity, deep seismic activity was again observed (fig. 2). The stress field at Mount St. Helens is investigated using the Gephart and Forsyth technique (1984). We assume that all the different fault-plane solutions within the entire volume are due either to a single uniform stress tensor orientation or, alternatively, have measurable changes in orientation for subvolumes of the region related to local sources of stress, such as a crustal magma chamber. Our procedure is: i) to divide the seismicity into subsets of the data as function of both depth and time, and ii) to determine the stress tensor orientation and its confidence limits for different groups of events. Our goal is the study of the stress source causing seismic release and its relation to the inferred magma system. 


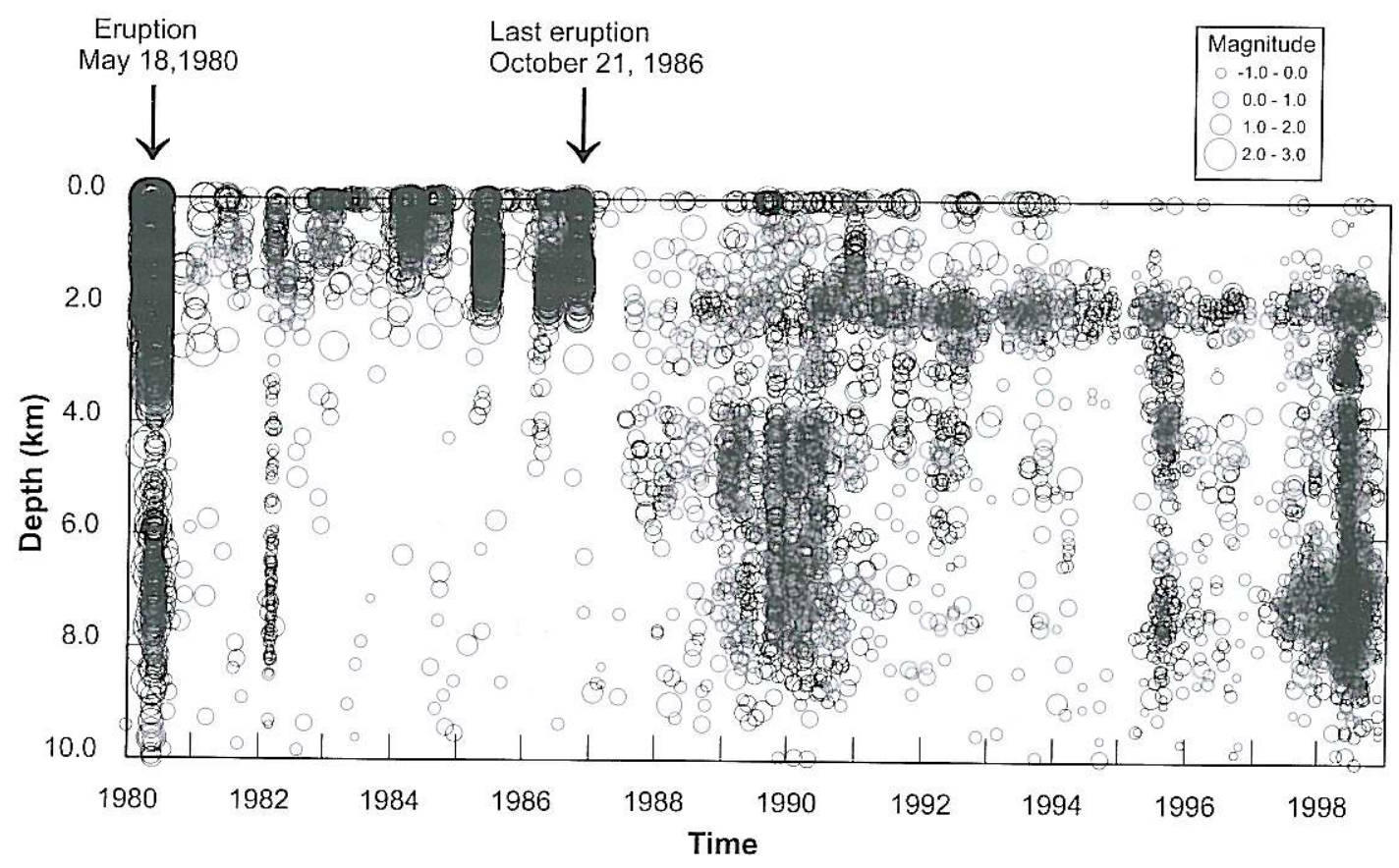

Fig. 2. Time-depth plot of all earthquakes beneath Mount St. Helens occurring between 1980 and 1998. Note that $0 \mathrm{~km}$ corresponds to mean station elevation, $1.6 \mathrm{~km}$ above sea level at MSH.

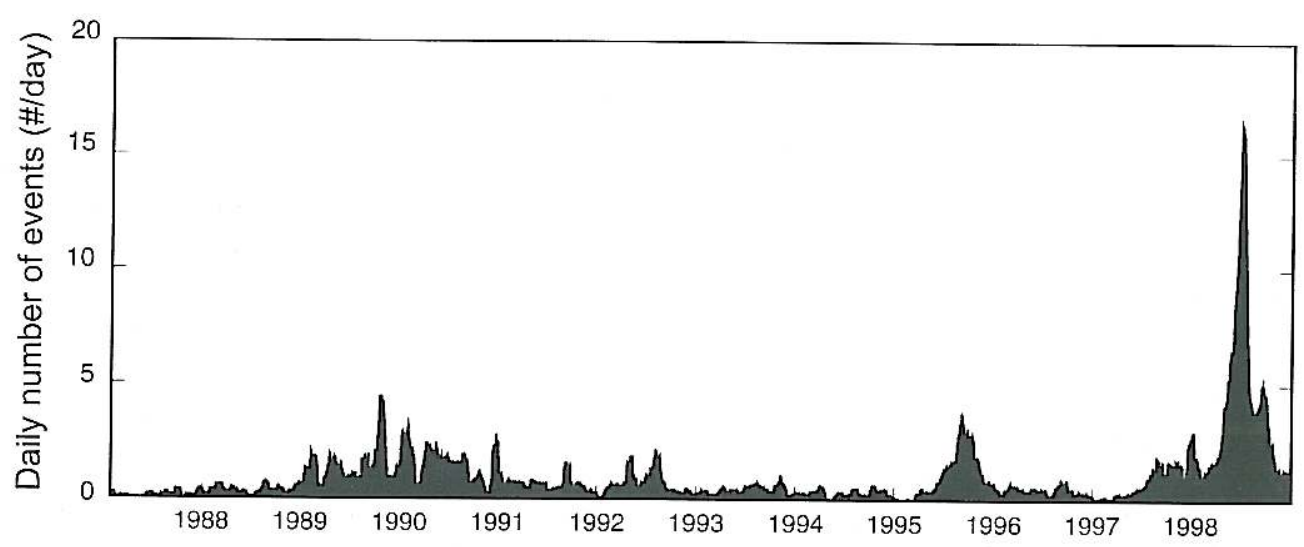

Fig. 3. Daily occurrence of the events in the years following the last eruption. 


\section{Tectonic setting}

Volcanoes of the Cascade Range represent the magmatic arc associated with the post-40 Ma subduction of the Juan de Fuca plate and its predecessors. Despite the fact that the Pacific Northwest has been an area of convergence throughout the Cenozoic (Atwater, 1970), volcanism accompanying this convergence has been discontinuous through time and has varied spatially along the strike of the subduction zone (McBirney, 1978; Luedke and Smith, 1982; Guffanti and Weaver, 1986). The modern range of Cascade volcanoes dates to approximately $1 \mathrm{Ma}$. Mount St. Helens itself began producing dacitic lavas only about 40000 years ago and has been the most active volcano in the Cascadian for the last 4000 years (Mullineaux and Crandell, 1981). The region is dominated by a succession of tectonic, igneous, and erosional events that determine the present complex of basalts, andesites, and quartz-diorites exposed at the surface (for more details about the geology of the Mount St. Helens region see reports by Evarts et al., 1987; Finn and Williams, 1987; Williams et al., 1987; Stanley et al., 1987).

To help clarify the tectonic setting and to delineate subsurface geologic features of the Mount St. Helens region, several geophysical studies have been published. Analysis of aeromagnetic data (Finn and Williams, 1987) and gravity data (Williams et al., 1987) indicate the presence of an anomalous, intrusive unit beneath the present volcano. Using conductivity data, Stanley et al. (1987) concluded that this anomalous unit overlies a system of sedimentary rocks described by Dickinson (1976). Stanley et al. (1987) further describe a large conductivity anomaly that trends north of St. Helens paralleling the St. Helens seismic zone (SHZ) as defined by Weaver and Smith (1983). Lees (1992) has observed a pronounced low velocity anomaly directly under the crater in layers deeper than 9 $\mathrm{km}$. However the resolution of the tomographic image is not sufficient to unambiguously associate this region with a magma chamber. Wiemer and McNutt (1997) observed a volume with high $b$-value in a depth range of about $6.7-9.0 \mathrm{~km}$. They proposed that the main cause of the increased $b$-value was likely the high thermal stress gradients in the vicinity of a magma chamber.

\section{Data collection and processing}

Seismic data collected at Mount St. Helens between 1995 and 1998 are analyzed in this study. During this period, more than 4000 earthquakes have been located by the Pacific Northwest Seismograph Network (see fig. $1 \mathrm{~b}$ for the distribution of the closest seismic stations to Mount St. Helens whereas for a detailed description of the network and routine data processing procedures see Ludwin et al., 1994). Among these earthquakes, 2089 events with more than $8 P$-wave arrivals were selected and used as the database for this study. Routine earthquake locations were obtained by using a modified version of the single value decomposition algorithm, «FASTHYPO» (Herrmann, 1979) in an eight layer, one-dimensional velocity structure (Malone and Pavlis, 1983).

The data consist of $P$-wave arrivals including first-motion polarities from earthquakes located within an area defined by a rectangle (fig. 1a) with coordinates 46.17-46.23 latitude (N) and 122.14-122.23 longitude (W). The depth of the events ranges from 0 to $10 \mathrm{~km}$ (fig. 2). Below $10 \mathrm{~km}$ the data are sparse (just 14 events were recorded in the period 1995-1998), and therefore they were not considered in this study.

An important initial step in selecting the earthquakes from the catalog was to remove low-frequency events and surface events such as rock-falls and avalanches which are commonly recorded at Mount St. Helens (Malone, 1983). It is noteworthy that only one low-frequency event has occurred on the volcano since 1995 (on September 13, 1998). Seismograms of promising events were reread by the authors to check polarities. Fault Plane Solutions (FPS) were determined using the FPFIT program by Reasenberg and Oppenheimer (1985). In order to obtain good azimuthal data coverage for each focal mechanism solution, a minimum of $8 \mathrm{im}$ pulsive $P$-wave first motions in different azimuth (12 on average) were required for each selected event. The FPFIT program constrains the mechanisms to be double-couple and performs a grid search over the available solution space. This assumption of double-couple solution appears not to be valid for some of the earthquakes at Mount St. Helens. However, all 


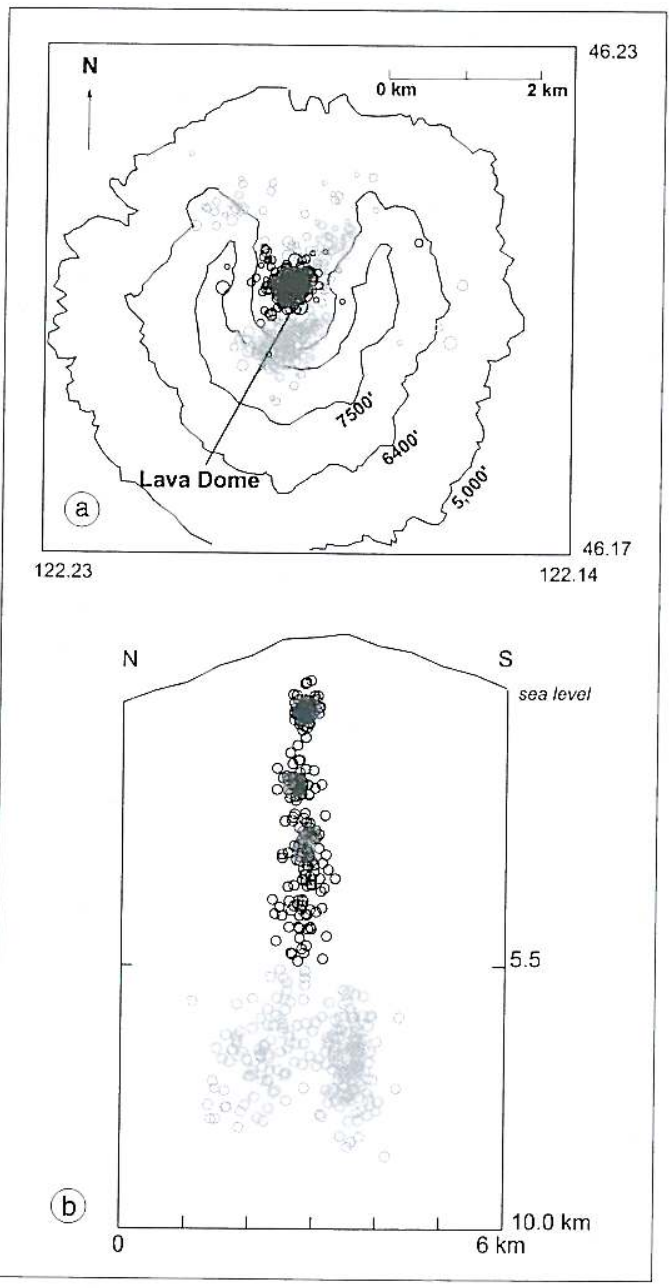

Fig. $4 a, b$. a) Location of the 459 events selected for the application of Gephart and Forsyth's algorithm. It can be noted that between $2-5.5 \mathrm{~km}$ they are concentrated beneath the lava dome (black open circles); while between $5.5-10 \mathrm{~km}$ they spread vertically from this area defining an aseismic zone to the west of the lava dome (grey open circles). b) N-S cross section of the 459 selected events. The reference for depth is an elevation of $1.6 \mathrm{~km}$, the average station elevation.

of the focal mechanisms used in this study are at least consistent with a double-couple solution, although other different solutions may not be always precluded. Further criteria were used to

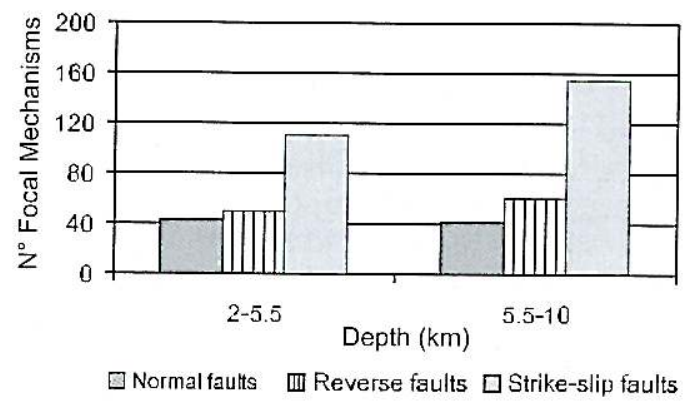

Fig. 5. Number of focal mechanisms as a function of depth. Strike-slip mechanisms are defined as solutions in which both the $P$ and $T$ axes plunge at angles less than $45^{\circ}$; normal and reverse mechanisms as solutions in which $P$ and $T$ axes plunge at angles greater than $45^{\circ}$, respectively.

select events: 1) a maximum station-azimuthal gap of 100 degrees; 2) a maximum RMS traveltime residual of $0.3 \mathrm{~s} ; 3$ ) horizontal location errors less than $1.0 \mathrm{~km}$ and vertical errors less than $2 \mathrm{~km}$; 4) only location quality $\mathrm{AA}, \mathrm{AB}, \mathrm{BA}$.

A total of 459 FPSs were considered suitable for the application of Gephart and Forsyth's algorithm (1984). These events are concentrated in a volume directly beneath the crater, in and around the inferred Mount St. Helens conduit system (fig. 4a). No events occurred in the very shallow region $0-2 \mathrm{~km}$ below the dome (fig. 4b). Events located below $5.5 \mathrm{~km}$ define a somewhat circular aseismic zone (fig. 4a), similar in location to ones observed after May 18, 1980 by Barker and Malone (1991) and for the period 1987-1992 by Moran (1994). This feature extends from $\sim 5.5 \mathrm{~km}$ down to $\sim 10 \mathrm{~km}$ and widens slightly with depth (fig. 4b). Since relative location errors for the earthquakes shown are small $(<1 \mathrm{~km}$ horizontal uncertainty), the aseismic zone is not an artifact of data error.

The focal mechanisms show a variety of fault plane solutions. More than $90 \%$ of the selected earthquakes have «AA» location qualities and consist of $56 \%$ strike slip faulting, $25 \%$ reverse faulting, and $19 \%$ normal faulting mechanisms (fig. 5). Some examples of focal mechanism solutions are shown in fig. 6 . 


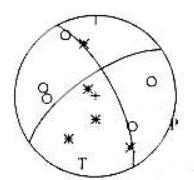

9504040251
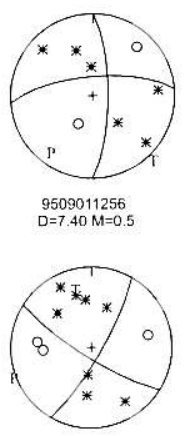

9605190216

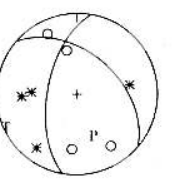

9710210429

$D=3.04 M=0.6$

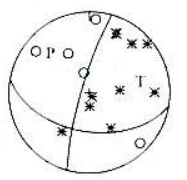

9801171119

$D=7.08 M=1.0$

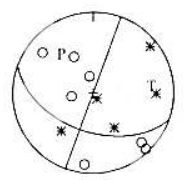

9806211104

$D=761 \mathrm{M}=0.6$

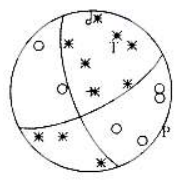

9807060053

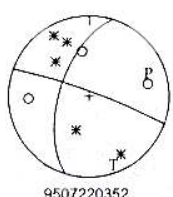

9507220352
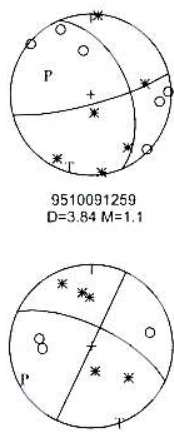

9608060509

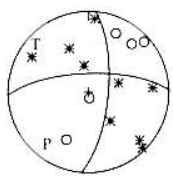

971003003

$D=7.29 M=0.6$

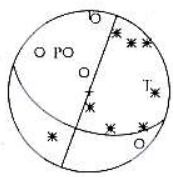

9801252108

$\mathrm{D}=7.03 \mathrm{M}=1.0$

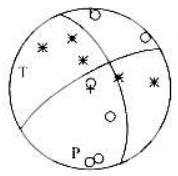

3807010309

$0=7.18 \mathrm{M}=0.7$

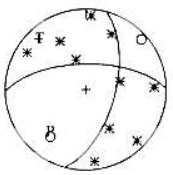

9807060247
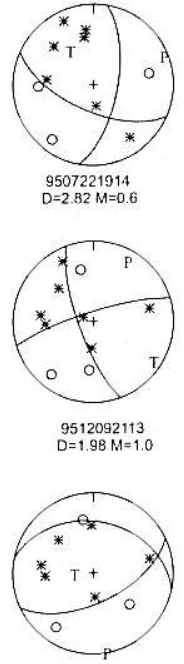

9609040216

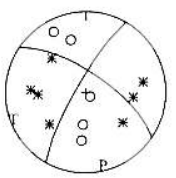

9711020100

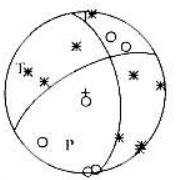

9803290744

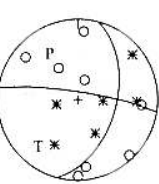

9807011649

$D=8.29 \mathrm{M} / 4=0.9$

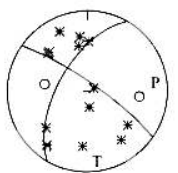

9807121130
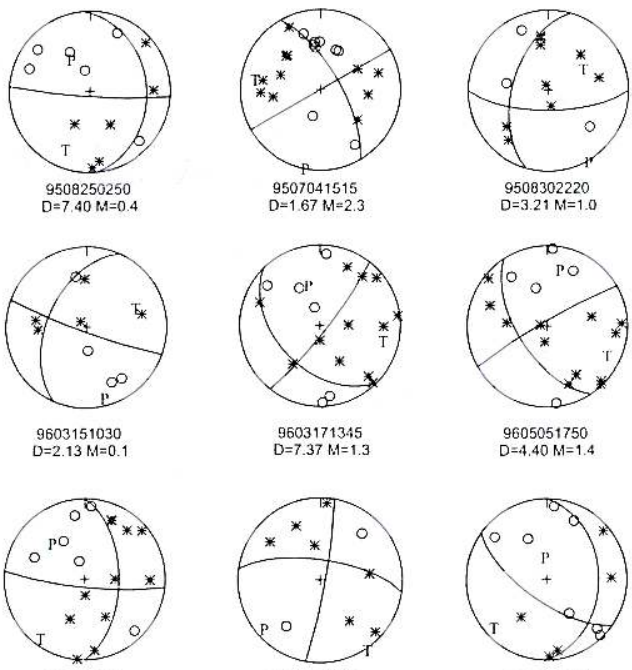

9707100951
$D=7.12 M-1.2$

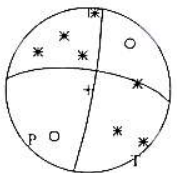

9708252137

$D=5.18 M=0.8$
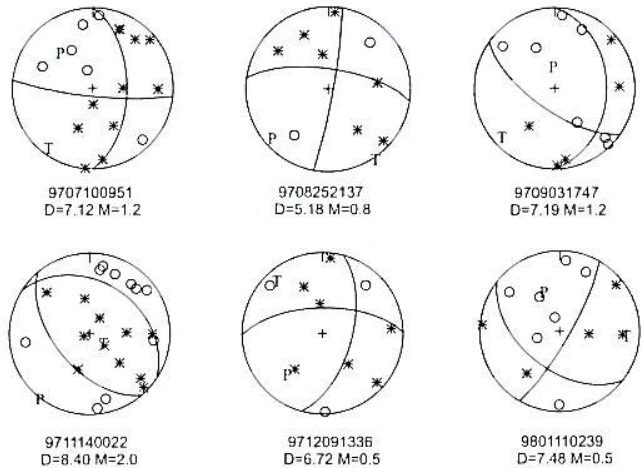

9712091336

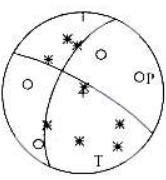

9804281557

$\mathrm{D}=1.88 \quad \mathrm{M}=0.8$

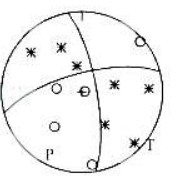

9607030033

$\mathrm{D}=6.78 \mathrm{M}=0.2$

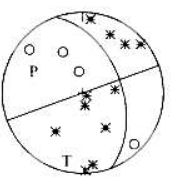

9809090943
$D=7.00 M=1.5$

\section{9}

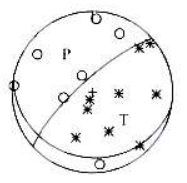

9806181552

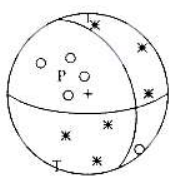

9807041259

$\mathrm{D}=8.08 \mathrm{M}=0.1$

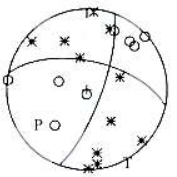
$D=6.37 M=1.5$
9811091846

Fig. 6. A plot of a representative first-motion solution for each year is shown. Lower hemisphere equal-area projection is used, with open circles and asterisks, dilatations and compressions, respectively. Earthquake date and time, depth and magnitude, are listed below each solution. 


\section{Stress tensor inversion}

To determine stress directions from fault plane solutions, we used the Focal Mechanism Stress Inversion (FMSI) computer program developed by Gephart and Forsyth (1984) and Gephart (1990).

This method is based on the following basic assumptions: 1) stress is uniform in the rock volume of the seismic sample investigated; 2) earthquakes are shear dislocations on pre-existing faults; 3 ) slip occurs in the direction of the resolved shear stress on the fault plane. Four stress parameters are calculated: three of them define the orientations of the main stress axes $\sigma_{1}, \sigma_{2}$ and $\sigma_{3}$, the other is a measure of relative stress magnitude $R=\left(\sigma_{2}-\sigma_{1}\right) /\left(\sigma_{3}-\sigma_{1}\right)$. Moreover, a variable misfit $(F)$ is introduced in order to define discrepancies between the stress tensor and the observed fault plane solutions. For a given stress model, the misfit of a single focal mechanism is defined as the smallest rotation around any arbitrary axis which brings one of the nodal planes, its slip direction and the sense of slip into an orientation that is consistent with the stress model.

Each FPS receives two misfits, one for each nodal plane. If an a priori choice of the fault plane is not made, the nodal plane with the smaller misfit is assumed as the fault plane. The size of the average misfit provides a guide of how well the assumption of stress homogeneity is fulfilled in relation to the seismic sample submitted to the inversion algorithm (Michael, 1987). In the light of the results from a series of tests carried out by Wyss et al. (1992), Gillard et al. (1996), Cocina et al., (1997) for identifying the relationship between FPS uncertainties and average misfit in the case of uniform stress, we assume that the condition of a homogeneous stress distribution is fulfilled if the misfit, $F$, is smaller than $6^{\circ}$ and that it is not fulfilled if $\mathrm{F}>9^{\circ}$. For $F$ values between $6^{\circ}$ and $9^{\circ}$ the solution is considered acceptable, but may reflect some heterogeneity. The statistical confidence limits established for possible stress orientations that are consistent with the observed focal mechanisms may give an additional contribution because they generally tend to enlarge for increasing stress heterogeneity (Cocina et al.,
1997). We computed the $90 \%$ confidence level using the statistical procedure described by Parker and McNutt (1980) and Gephart and Forsyth (1984). The size of the $90 \%$ confidence limits will not be a criterion for preferring an inversion result, because it does not measure the quality of the result but rather the degree to which it is constrained.

\section{Stress tensor analysis}

Previous analyses of focal mechanisms have been carried out in the U.S. Northwest region by Ma et al. (1991) and Giampiccolo et al. (1999). Ma et al. (1991) used crustal earthquakes (less than $30 \mathrm{~km}$ depth) in the North America plate between the Puget Sound and the Mount St. Helens region. A uniform roughly north-south compressive tectonic stress in the crust adequately explains all of the observed focal mechanisms in Western Washington. Giampiccolo et al. (1999) used crustal earthquakes in the Central Washington Cascade Mountains. Similarly, the maximum compressive stress axis, $\sigma_{1}$, is nearly horizontal and trending N-S to NNESSW. In the present study, the inversion algorithm of Gephart and Forsyth (1984) is applied to 459 fault-plane solutions. If they are produced by a single stress tensor, then the variety among the fault plane solutions may be the result of the presence of planes of weakness with different orientations to accommodate the slip. On the other hand, the variation could reflect the inhomogeneity of stress within the crust.

Each of the FPS was assigned a weight $(1=$ sufficiently constrained; 2 = well constrained) based on a qualitative evaluation of the polarity distribution and score. Fault parameter uncertainties range between 5 and 20 degrees, with the great majority of cases between 10 and 15 degree. The initial inversion consisted of a search of the entire range of possible stress orientations on a 10-degree grid using the approximate method. The regions of possible solutions suggested by the approximate method were then searched more thoroughly using the exact method on a 5 -degree grid. The ratio $R$ was searched at intervals of 0.1 . 
First, the entire set of events was inverted and a nearly W-E direction for $\sigma_{1}$ was obtained (data set 1 in table I). Although the $90 \%$ confidence areas for the maximum $\left(\sigma_{1}\right)$ and for the minimum stresses $\left(\sigma_{3}\right)$ are rather small (fig. 7) and the $R$ parameter is well constrained, the misfit value $F=11.5$ is too large to be accepted as representative of a homogeneous stress field on the basis of our criteria. Below we will examine whether subsets of the data, corresponding to space sub volumes and/or time subintervals, will provide a smaller average misfit. If so, the subsets would represent regions of more homogeneous stress field than the total set.

Seeking reduction of average misfit and confidence limits (reduction of heterogeneity), two methods were followed. First, it was hypothesized that the directions of the stress field could be changed with depth. To test this hypothesis the data set of focal mechanisms was subjectively divided into two subsets (data sets $2 a-b$ in table I) as a function of depth based on an apparent change at $6 \mathrm{~km}$ depth seen in the seismicity distribution (fig. 4b). Then the best constrained FPSs of each subset were inverted. Second, we used a technique for estimating changes of stress directions from changes in the slope of the cumulative misfit graph (Wyss and Lu, 1995).

For each set several tests were performed by using different grid steps and a large variety of starting values for the stress parameters in order to check the reliability of the results. For the first investigated sub volume $(2-6 \mathrm{~km}$ depth, data set 2a in table I), we inverted 204 focal mechanisms obtaining a fairly large value of misfit. Then the subset $6-10 \mathrm{~km}$ depth (data set $2 b$ in table I) was investigated. In both cases the $F$ values (15.2 and 8.4, respectively) suggested that an uniform stress configuration is not able to explain the experimental data.

Since the attempt to divide subjectively the data set as a function of space did not produce significant reduction of the average misfit, and

Table I. Stress tensor results from the inversions of the fault plane solutions. $N$ indicates the number of events; $F$ is the average misfit angle; $\sigma_{1}, \sigma_{2}$, and $\sigma_{3}$, indicate the greatest principal stress, the intermediate principal stress, and the least principal stress, respectively; $\mathrm{Az}$ is the azimuth; $\mathrm{Pl}$ is the plunge; $R$ is the magnitude ratio of principal stresses (see text). Data sets: $1=$ all events considered suitable for the inversion; $2 \mathrm{a}=$ events with focal depth $z<6 \mathrm{~km} ; 2 \mathrm{~b}=$ events with focal depth $z \geq 6 \mathrm{~km} ; 3 \mathrm{a}=$ events with focal depth $z<5.5 \mathrm{~km} ; 3 \mathrm{~b}=$ events with focal depth $z \geq 5.5 \mathrm{~km} ; 4 \mathrm{a}=$ all events located within the NW ellipsoidal region indicated in fig. $12 ; 4 \mathrm{~b}=$ all events located within the NE ellipsoidal region indicated in fig. $12 ; 4 \mathrm{c}=$ all events located within the SOUTH ellipsoidal region indicated in fig. 12;5a = events located within the NW ellipsoidal region indicated in fig. 12;5b=events located within the NE ellipsoidal region indicated in fig. $12 ; 5 \mathrm{c}=$ events located within the SOUTH ellipsoidal region indicated in fig. 12 (see text for more details).

\begin{tabular}{|c|c|c|c|c|c|c|c|c|c|}
\hline \multirow{2}{*}{ Data set } & \multirow{2}{*}{$N$} & \multirow{2}{*}{$F\left({ }^{\circ}\right)$} & \multicolumn{2}{|c|}{$\sigma_{1}$} & \multicolumn{2}{|c|}{$\sigma_{2}$} & \multicolumn{2}{|c|}{$\sigma_{3}$} & \multirow{2}{*}{$R$} \\
\hline & & & $\mathrm{Az}\left({ }^{\circ}\right)$ & $\mathrm{Pl}\left({ }^{\circ}\right)$ & $\mathrm{Az}\left(\left(^{\circ}\right)\right.$ & $\mathrm{Pl}\left({ }^{\circ}\right)$ & $\mathrm{Az}\left({ }^{\circ}\right)$ & $\operatorname{Pl}\left({ }^{\circ}\right)$ & \\
\hline 1 & 459 & 11.5 & 262 & 58 & 7 & 9 & 103 & 30 & 0.6 \\
\hline $2 a$ & 204 & 15.2 & 256 & 49 & 32 & 32 & 137 & 23 & 0.7 \\
\hline $2 b$ & 255 & 8.4 & 270 & 60 & 5 & 3 & 97 & 30 & 0.6 \\
\hline $3 a$ & 186 & 15.0 & 322 & 31 & 213 & 29 & 90 & 45 & 0.9 \\
\hline $3 b$ & 273 & 8.3 & 266 & 59 & 6 & 6 & 99 & 30 & 0.6 \\
\hline $4 a$ & 16 & 3.5 & 184 & 27 & 71 & 37 & 300 & 41 & 0.7 \\
\hline $4 b$ & 92 & 6.4 & 231 & 32 & 109 & 40 & 345 & 33 & 0.7 \\
\hline $4 c$ & 165 & 6.1 & 328 & 35 & 85 & 33 & 205 & 38 & 0.5 \\
\hline $5 a$ & 15 & 2.5 & 322 & 5 & 223 & 61 & 55 & 28 & 0.9 \\
\hline $5 b$ & 89 & 5.7 & 231 & 32 & 108 & 41 & 344 & 32 & 0.7 \\
\hline $5 c$ & 161 & 5.7 & 328 & 35 & 83 & 31 & 203 & 40 & 0.5 \\
\hline
\end{tabular}



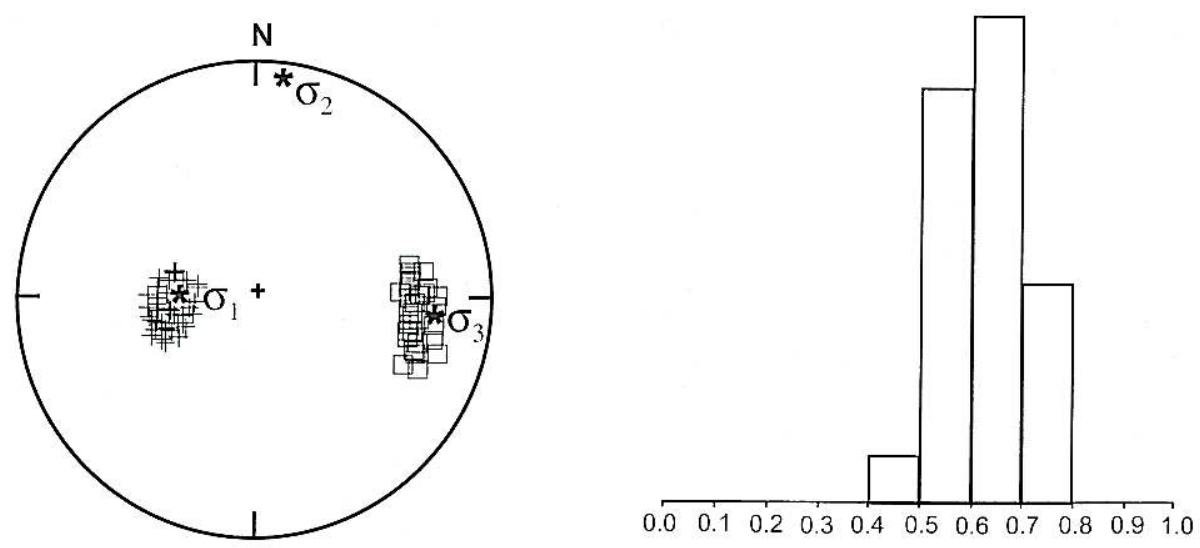

Fig. 7. Directions of principal stresses, $\sigma_{1}, \sigma_{2}$, and $\sigma_{3}$ (stars) for data set 1 . The bar graph shows the $90 \%$ confidence limits of the $R$-parameter in terms of frequency distributions between the extreme values 0 and 1 .

considering the problems encountered in trying to identify subintervals characterized by uniform stress over the whole period of investigation, we tried a more quantitative method, introduced by Wyss and $\mathrm{Lu}$ (1995), to find temporal or spatial distributions of stress which might reduce the misfit.

\subsection{Estimate of stress direction changes by cumulative misfit as a function of time}

The method of Wyss and Lu (1995) is broadly used to investigate stress homogeneity. It is based on the cumulative misfit of individual fault plane solutions, calculated using an assumed stress tensor. Using this method, subintervals and/or sub volumes can be defined without the time-consuming inversions for stress directions. We assume that the misfits are relatively constant within segments of uniform stress orientation. The extent of segments with homogeneous stress-directions is determined from changes in slope of the cumulative misfit, $\sum f(x)$, calculated on the basis of a reference-stresstensor which can be an assumed one, approximately fitting the tectonic setting, or it can be the stress-tensor fitting any individual segment. Ends of segments will be considered as defined if their relatively constant slopes of $\sum f(x)$ is different from that of the neighboring segment above the $95 \%$ confidence level, as judged by the standard deviate $Z$-test (Davis, 1986). Final$1 y$, the stress directions can be estimated for each segment separately by inversion from fault plane solutions within a limited crustal volume. The segmentation analysis will be considered successful if the inversions for the stress-directions in the individual segments yield $F_{i}<6^{\circ}$ and $F_{i}<F$ (over all), where $i$ is the segment number.

Therefore, the stress field time evolution was investigated by plotting the cumulative misfit $f(N)$ as

$$
f(N) \sum f_{i} \quad i=1,2, \ldots \ldots, N
$$

as a function of the event order number $N$ (where $1 \leq N \leq 459$ ), $f$ being the misfit of the $i$-th FPS with respect to a test stress tensor. The standard deviate Z-test (Davis, 1986) was used to investigate whether the mean misfits for two periods are equal to each other and, if not, to determine 
the event numbers of greatest change and the statistical significance of the change. For two periods, 1 and $2, Z$ is given by

$$
Z=\left(F_{1}-F_{2}\right) / \sqrt{\left(s_{1}^{2} / n_{1}+s_{2}^{2} / n_{2}\right)}
$$

where $F$ is the mean misfit, $s$ its standard deviation, and $n$ the number of samples (Slejko et al., 1999). The two means $F_{1}$ and $F_{2}$ will be different at a level of significance of $99 \%$ if $Z>2.3$. By using the overall average stress direction as a test tensor and applying the $Z$-test to the data set ordered in time, no significant difference in misfit was found (fig. 8, curve a). Similarly, the cumulative misfit curve based on the test tensor best fitting the intense period of seismicity (MayJuly 1998) does not show any clear temporal change (fig. 8 , curve b). As shown in fig. 8 the cumulative misfit curves have a rather constant slope, this means that it is not possible to find subintervals with significant improvements in terms of stress uniformity.

\subsection{Estimate of stress direction changes by cumulative misfit as a function of depth}

Using the overall average stress directions as a test tensor the cumulative misfit as a function of depth is shown in fig. 9 (see curve a). The most significant change of the slope of the cumulative misfit takes place at event no. 189 which corresponds to a depth of $5.5 \mathrm{~km}$ (dashed line). Within the two segments the stress directions are uniform with a relatively constant misfit for all earthquakes. The different slope of the two segments allows us to state with confidence levels above $99 \%$ that differences in stress directions exist at different depths. Repeating the same routine starting from sample 189 (after exclusion of samples 1-188) does not lead to identification of other important slope changes. A series of tests of this procedure on synthetic data sets is reported in Lu et al. (1997). To verify the apparent segmentation in fig. 9, curve a, and to possibly detect further segmentations, we calculated the cumulative misfit curve using the test tensor best fitting the sub volume in the depth

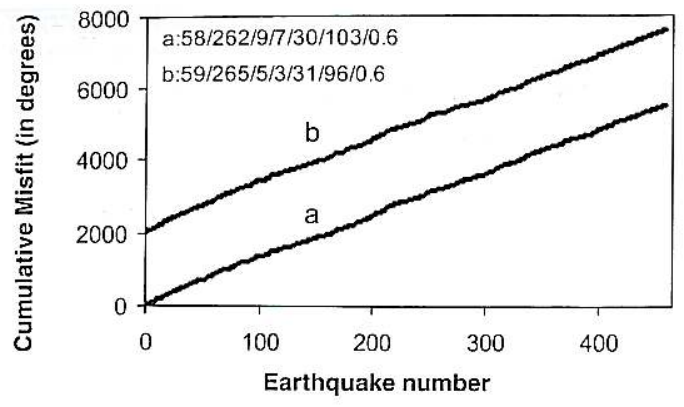

Fig. 8. Cumulative misfit $\sum f(N)$ as a function of earthquake numbers ordered in time. Individual misfits have been computed: a) with respect to the stress direction of data set 1; b) with respect to the stress direction of the intense period of seismicity (MayJuly 1998). The reference stress tensors used to calculate the misfit of individual earthquakes are shown in the upper left corner. These stress tensors are represented by plunge and azimuth of $\sigma_{1}, \sigma_{2}, \sigma_{3}$, and $R$ (see text). The b curve has been shifted upward for clarity.

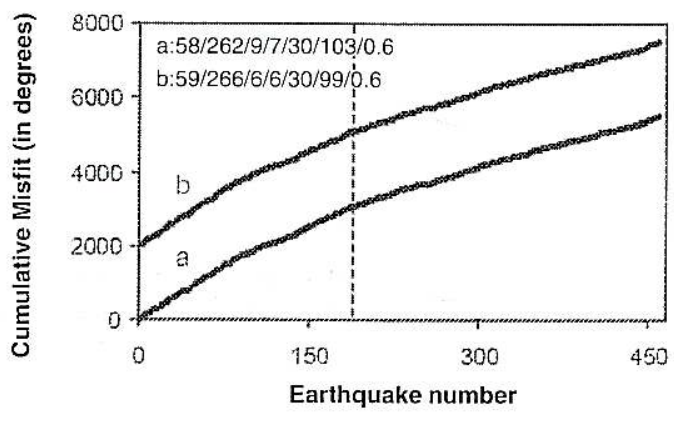

Fig. 9. Cumulative misfit $\sum f(N)$ as a function of earthquake numbers ordered in depth. Individual misfits have been computed: a) with respect to the stress direction of data set 1 ; b) with respect to the stress direction of data set $3 \mathrm{~b}$. The $\mathrm{b}$ curve has been shifted upward for clarity.

range $5.5-10 \mathrm{~km}$ (fig. 9, curve b). Again, the cumulative misfit curve shows a significant slope change in correspondence of the sample 189.

By using the quantitative method, we introduced a refinement in finding, in a meaningful 
way, a depth boundary between different stress populations. This slightly changed our qualitative boundary of $6 \mathrm{~km}$ to a shallower one of 5.5 $\mathrm{km}$. Then we selected the two subsets of events (data set 3a,b in table I) that have approximately uniform misfits (constant slope). Inversions of the data led to average misfits of $F=15.0$ and $F=8.3$ for the two depth-volumes, respectively (fig. 10a,b). Although the two solutions in the new segments have $F$ values too large, the dif- ference is significant at the $99 \%$ level in the cumulative misfit curves (fig. 9). We then assumed that the stress in these volumes is heterogeneous $\left(F>6^{\circ}\right)$, considering that the FPSs in the study area are of high quality. An invalid stress tensor may be obtained if the data are composed of sets from more than one volume with significantly different stress orientations. Our purpose is to define accurately these sub volumes.
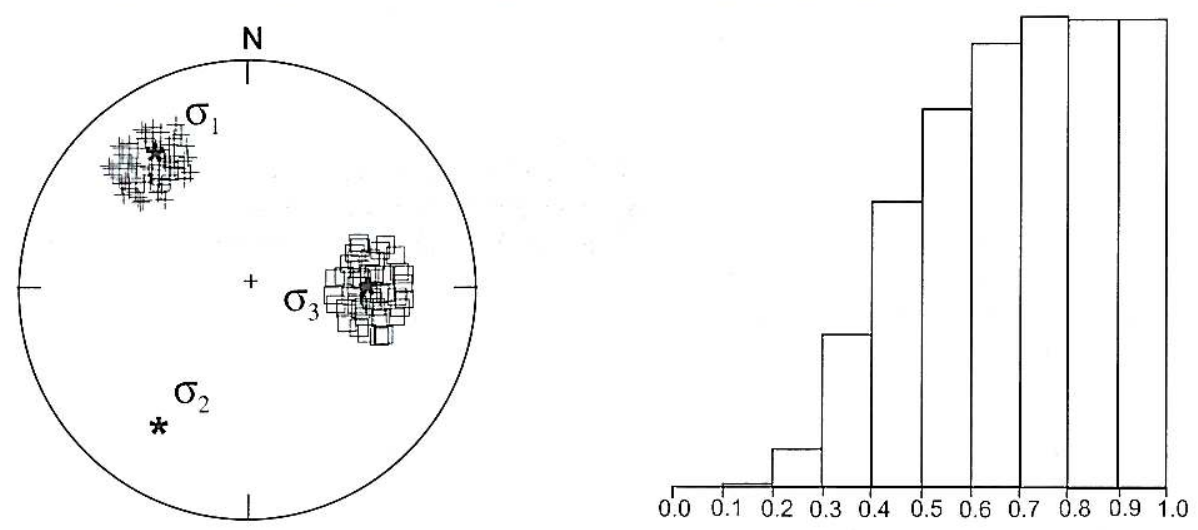

(a) $2-5.5 \mathrm{~km}$
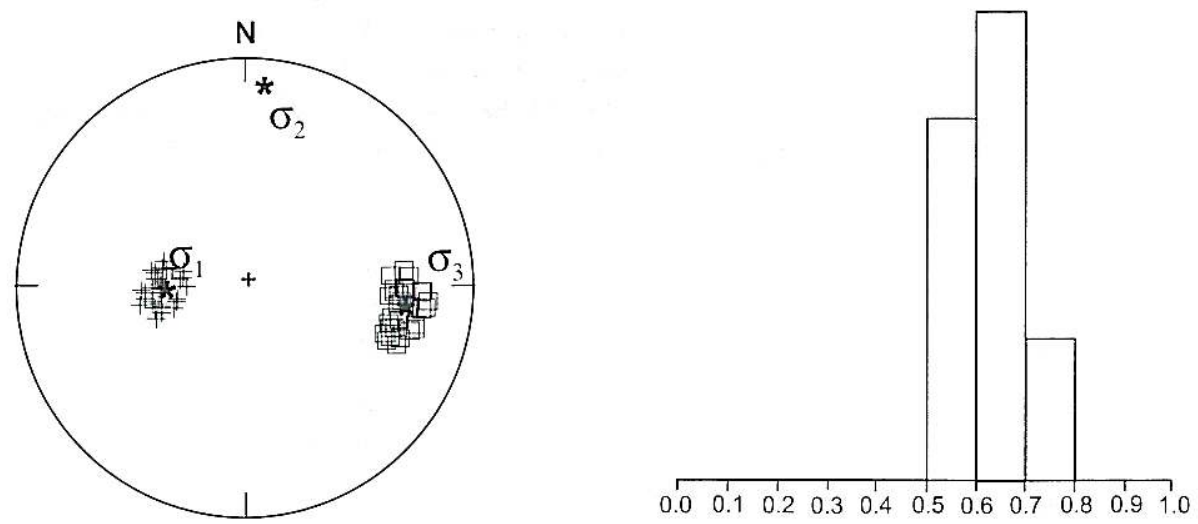

(b) $5.5-10 \mathrm{~km}$

Fig. 10a,b. Directions of principal stresses, $\sigma_{1}, \sigma_{2}$, and $\sigma_{3}$ (stars) for data set $3 \mathrm{a}, \mathrm{b}$. The bar graph shows the $90 \%$ confidence limits of the $R$-parameter in terms of frequency distributions between the extreme values 0 and 1 . 


\subsection{Estimate of stress direction changes by cumulative misfit as a function of areal distribution}

Since the stress does not seem homogeneous for any data set, subsets corresponding to spatial sub volumes were inverted. Looking at fig. 11 a, no single $P$ axis trend dominates in the range $2-5.5 \mathrm{~km}$. Conversely, the compressional axes, in the range $5.5-10 \mathrm{~km}$ (fig. 11b), point radially away from the center of the 1995-1998 aseismic zone. These patterns are considered to be the result of the ambient stress field over some volume. It is interesting to observe the similar distribution of $P$-axes between the analyzed period (1995-1998) and that one of 19871992 (as reported in Moran, 1994). In both cases the $P$-axes point radially away from the center of the aseismic zones (fig. 12).

Using the $P$-axis distribution, the data set in the range $5.5-10 \mathrm{~km}$ was subdivided into three subsets corresponding to the ellipsoidal regions indicated in fig. 12 and labeled NW, NE and SOUTH. These subsets (4a-c in table I) include all earthquakes located within the ellipses shown in fig. 12. We have found that the stress directions of each subset are significantly different from each other and the average misfits in these volumes are very small. The reduction of the average mis-

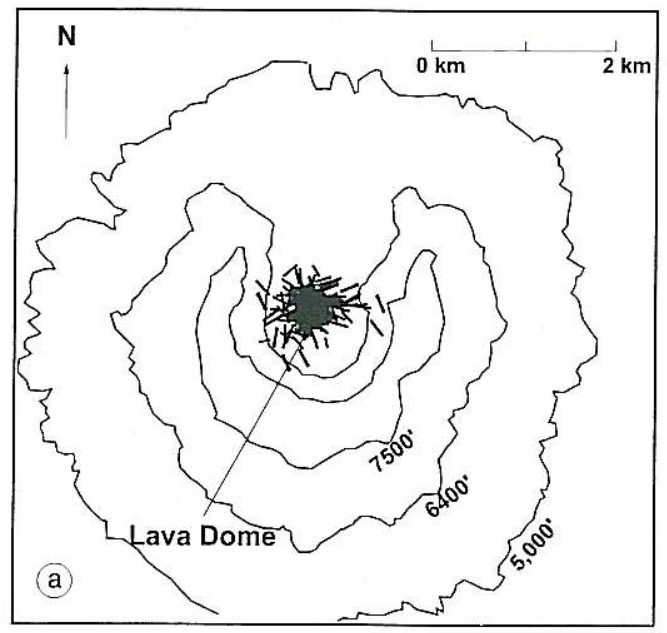

fit from $8.3^{\circ}$ for the whole data set to values in the range $3.5^{\circ} \leq F \leq 6.4^{\circ}$ in subsets (data set $4 \mathrm{a}-\mathrm{c}$, table I) suggests that the stress directions are heterogeneous in the studied area, while they are uniform in the NW sub volume and such a condition is close to being fulfilled in the NE and SOUTH sub volumes even though some heterogeneity seems to be present. Although these misfits are small enough to satisfy our criterion for acceptably homogeneous data sets, the technique of estimating changes of stress directions from changes in the slope of the cumulative misfit graph was used to confirm this subdivision.

On the basis of preliminary exploration we decided to consider three profiles as a function of the $P$-axes distribution. The earthquakes were ordered from south to north for growing latitude, including the events located within the ellipses SOUTH and NE (profile A). In the profile $\mathrm{B}$ the earthquakes were ordered from east to west for growing longitude, including the events located within the ellipses NE and NW. In the final step of the search we ordered the events from south to northwest for growing latitude, including the events located within the ellipses SOUTH and NW (profile C). Analysis with different reference stress models helped to define the stress segmentation boundaries. The constancy of slope in individual segments (fig. 13a-c) is

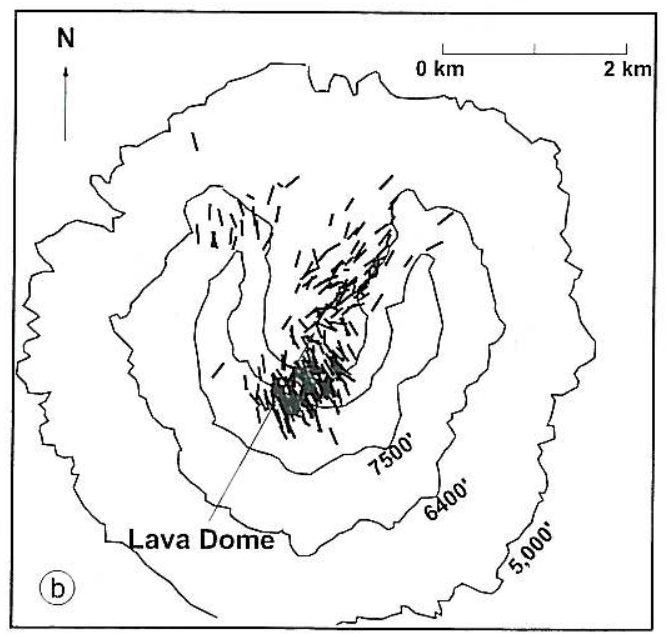

Fig. 11a,b. Horizontal projections of $P$-axes in the depth range: a) $2-5.5 \mathrm{~km}$; b) $5.5-10 \mathrm{~km}$. 


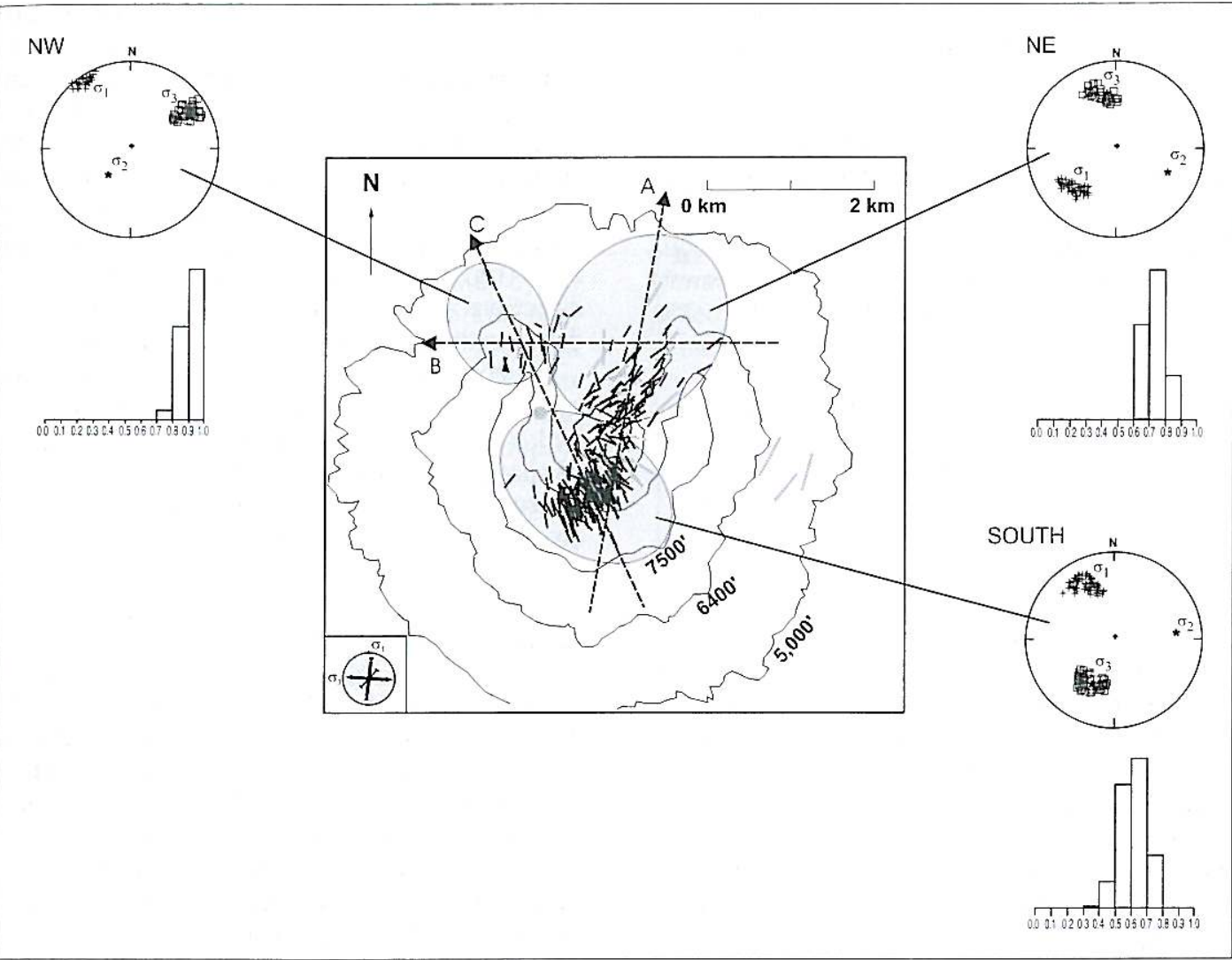

Fig. 12. Horizontal projections of $P$-axes in the depth range 5.5-10 km (black line) and 1987-1992 period as reported in Moran (1994) (grey line). The grey solid circle corresponds to the best chamber location determined from modeling by Moran (1994). A, B, and C represent the three profiles used to investigate the change in stress direction using the cumulative misfit graphs. Directions of principal stresses, $\sigma_{1}, \sigma_{2}$, and $\sigma_{3}$ (stars) for the three subsets 5a-c are also shown. The inset shows the regional stress field directions (from Ma et al., 1991).

remarkable, and so is the contrast between segments. As an example, in the profile A (fig. 13a) we can observe that approximately half of the individual misfits (see curve 1) are due to a mismatch between the test stress tensor used and the best-fitting tensor for all events after the dashed line. We conclude that the stress directions have changed as a function of areal distribution and the changes of the slopes in the cumulative plots are interpreted as boundaries in the stress directions.

It is interesting to observe that all three boundaries, that we chose subjectively, were also de- fined by the quantitative method. We also noticed that misfits from earthquakes located at the periphery of the volumes were often large. Therefore, we excluded some of the events located near the segmentation boundaries from the final inversions of both neighboring segments because these events did not fit either of the stress tensors of the neighboring segments. The average misfit decreases to $F=2.5, F=5.7$ and $F=5.7$ in the northwestern, northeastern and south volumes, respectively (data set $5 \mathrm{a}-\mathrm{c}$ in table I and fig. 12), when the data are inverted separately for the three sub volumes. For the 

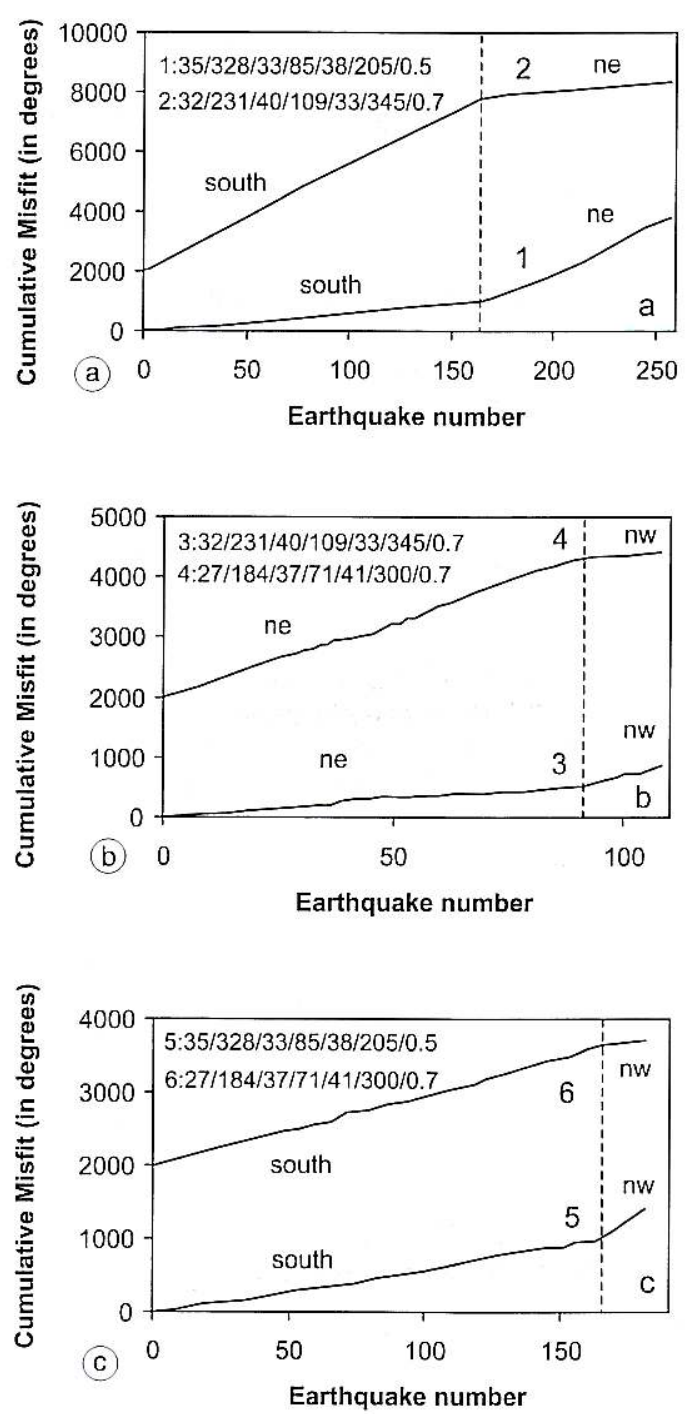

Fig. 13a-c. Cumulative misfit $f(N)$ as a function of earthquake numbers ordered in space. Individual misfits have been computed: a) for profile A; b) for profile $\mathrm{B}$, and $\mathrm{c}$ ) for profile $\mathrm{C}$. The reference stress tensors used to calculate the misfit of individual earthquakes are shown in the upper left corner. These stress tensors are represented by plunge and azimuth of $\sigma_{1}, \sigma_{2}, \sigma_{3}$, and $R$ (see text). Each segment (labeled nw, ne, and south) includes the earthquakes located within the ellipses shown in fig. 12. The curves 2,4 and 6 have been shifted upward for clarity.
NW subset the maximum compressive stress axis, $\sigma_{1}$, is nearly horizontal and trending NNWSSE. In the NE volume, $\sigma_{1}$ points toward SW. In the southern volume the direction of $\sigma_{1}$ is NNWSSE. In the fig. 12 it can be observed that for the three subsets, well constrained values of $R$ were found. Note that the resolved stress field supports a $\sigma_{1}$ approximately radial to the aseismic zone (fig. 12). The great stability of the stress directions in subsets of the data gives confidence in the reliability of the solutions obtained.

In contrast, the stress orientations revealed by the shallower earthquakes $(2-5.5 \mathrm{~km})$ exhibited a great deal of heterogeneity as a function of space. We believe that this is due to a highly fractured medium, making the sub volumes heterogeneous.

\section{Discussion and conclusions}

The method of plotting the cumulative misfit as a function of earthquake numbers, ordered in time, depth and space, was used for investigating the stress homogeneity at Mount St. Helens. The focal mechanisms data in the stress-homogeneous segments were then used to invert the principal stress orientation using FMSI computer code of Gephart (1990).

The results of the spatial stress tensor analysis in the Mount St. Helens area yielded a stress field consistent with a center of pressure in the aseismic zone. This increased pressure in the whole system gives as results: i) an inhomogeneous stress field due to the response of a highly fractured medium to increased gas pressure between 2 and $5.5 \mathrm{~km}$, and ii) a radial compressive stress field at depth $5.5-10 \mathrm{~km}$. A variation in stress field radial to the dome, with the maximum compressional axes rotated towards the dome, is expected if the stress from a magma chamber has a strong influence on the occurrence of the earthquakes. Therefore, the events located between 2 and $5.5 \mathrm{~km}$ can be interpreted as surrounding a narrow conduit connecting the surface with the deeper magma system below $5.5 \mathrm{~km}$. This result is in agreement with findings from previous investigations carried out using different data and different methodologies (see also Section 2). Scandone and Malone 
(1985), using the distribution of earthquake in the crust below Mount St. Helens, hypothesized a deep reservoir $(7-9 \mathrm{~km})$ connected to the surface by a conduit with a radius of approximately $50 \mathrm{~m}$. Earthquake focal mechanisms have also been used to model a $5-7 \mathrm{~km}^{3}$ magma body between 7 and $11 \mathrm{~km}$ depth (Barker and Malone, 1991). Modeling of the stress field supported the conclusion that the magma body was cylindrically shaped with a radius of $0.75 \mathrm{~km}$. Moran (1994) confirmed the previously accepted models (Scandone and Malone, 1985; Barker and Malone, 1991) and the hypothesis that the aseismic zone, between $6.5-10 \mathrm{~km}$, may represent a roughly cylindrical magma chamber within which the pressure changed from a decrease immediately following the explosive eruptions of 1980 to an increasing pressure starting in the late $1980 \mathrm{~s}$.

In contrast, the stress tensor inversion as a function of time did not reveal any significant change of the stress field with time over the four year period of this study. In view of the fact that there were no changes since 1995 , we may hypothesize that the geometry of the magmatic system did not evolve with time. On the other hand, although airborne surveys of volcanic gases revealed, between May and July 1998, high levels of $\mathrm{CO}_{2}$, probably reflecting degassing of a replenishing magma reservoir, ground deformation studies did not detect any movement in response to the increased level of seismicity occurring between May and July 1998 (Dzurisin, personal communication, 1998).

In the light of these results, the processes controlling the mechanics of the seismicity at Mount St. Helens seem to be related to the response of a brittle crustal rock to a pressure increase in the magma chamber. However further detailed analyses on a longer time period of data and different approaches may be useful to add constrains on the time-dependent changes of the magma conduit system.

\section{Acknowledgements}

We are grateful to the staff of the Pacific Northwest Seismograph Network for their effort to provide high quality recording of earth- quakes. We also wish to thank two anonymous referees for their careful review. This research started by the visit of S.G. at the Geophysics Program in Seattle in March 1996; the visit was supported by CNR. Data acquisition and analysis was funded by USGS cooperative agreements such as 1434-95-A-1302. Research supports come from Catania University grants (fondi di Ateneo-1998, ex 60\%). C.M. was assisted by a fellowship from «La Sapienza» University of Rome.

\section{REFERENCES}

ATWATER, T. (1970): Implications of plate tectonics for the Cenozoic tectonic evolution of Western North America, Geol. Soc. Am. Bull., 81, 3513-3536.

BARKER, S.E. and S.D. MALONE (1991): Magmatic system geometry at Mount St. Helens modeled from the stress field associated with posteruptive earthquakes, $J$. Geophys. Res., 96, 11883-11894.

Cocina, O., G. Neri, E. Privitera and S. Spampinato (1997): Stress tensor computations in the Mount Etna area (Southern Italy) and tectonic implications, $J$. Geodyn., 23 (2), 109-127.

DAvis, J.C. (1986): Statistics and Data Analysis in Geology (John Wiley \& Sons, New York), second edition, pp. 646.

DICKINSON, W.R. (1976): Sedimentary basins developed during evolution of Mesozoic-Cenozoic arc-trench system in Western North America, Can. J. Earth Sci., 13, 1268-1283.

Evarts, R.C., R.P. Asiley and J.G. SMITH (1987): Geology of the Mount St. Helens area: record of discontinuous volcanic and plutonic activity in the Cascade arc of southern Washington, J. Geophys. Res., 92, 10155-10169.

FINN, C. and D.L. WILLIAMS (1987): An acromagnetic study of Mount St. Helens, J. Geophys. Res., 92, 1019410206.

GephaRT, J.W. (1990): Stress and the direction of slip on fault planes, Tectonics, 9, 845-858.

GEPHART, J.W. and D.W FORSYTH (1984): An improved method for determining the regional stress tensor using earthquake focal mechanism data: application to the San Fernando earthquake sequence, J. Geophys. Res., 89, 9305-9320.

Giampiccolo, E., C. Musumeci, S.D. Malone, S. Gresta and E. Privitera (1999): Seismicity and stress tensor inversion in the Central Washington Cascade Mountains (U.S.A.), Bull. Seismol. Soc. Am., 89 (3), 811-821.

GIILARD, D., M. WYSS and P. OKubo (1996): Type of faulting and orientation of stress and strain as a function of space and time in Kilauea's south flank, Haway, J. Geoplys. Res., 101 (B7), 16025-16042.

GuFFanTI, M. and C.S. WEAver (1986): Distribution of late Cenozoic volcanic vents in the Cascade range and northwestern basin and range province (abstract), Eos, Trans. Am. Geophys. Un., 67, 1226. 
HERRMANN, R.B. (1979): FASTHYPO-a hypocenter location program, Earthquake Notes, 50 (2), 25-37.

LEES, J.M. (1992): The magma system of Mount St. Helens: non-linear high resolution wave tomography, J. Volcanol. Geotherm. Res., 53, 103-116.

LU, Z., M. WYSS and H. PULPAN (1997): Details of stress directions in the Alaska subduction zone from fault plane solutions, J. Geophys. Res., 102, 5385-5402.

LUDWIN, R.S., A.I. QAMAR, S.D. MALONE, C. JONIENTZTRISLER, R.S. CROSSON, R. BENSON and S.C. MORAN (1994): Earthquake hypocenters in Washington and Northern Oregon, 1987-1989, and operation of the Washington regional seismograph network, Wash. Div. Geol. Earth Res. Inf. Cir., 89, p. 40.

LuedKe, R.G. and R.L. Smiti (1982): Map showing distribution, composition and age of late Cenozoic volcanic centers in Oregon and Washington, U.S. Geol. Surv. Map, I-109I-D.

MA, L., R. Crosson and R.S. Ludwin (1991): Focal mechanisms of Western Washington earthquakes and their relationship to regional tectonic stress, U.S. Geol. Surv. Open-File Rep., 91-441-D.

MaLone, S.D. (1983): Volcanic earthquakes: examples from Mount St. Helens, Rend. Soc. It. Fis., 85, 436-455.

Malone, S.D. and G.L. PAVLis (1983): Velocity structure and relocation of earthquakes at Mount St. Helens, Eos Trans. Am. Geophys. Un., 64, 895.

MCBIRNEY, A.R. (1978): Volcanic evolution of the Cascade Range, Ann. Rev. Earth Planet. Sci., 6, 437-456.

MiCHAEI, A.J. (1987): Use of focal mechanisms to determine stress: a control study, J. Geophys. Res., 92, 357-368.

MORAN, S.C. (1994): Seismicity at Mount St. Helens, 19871992: evidence for repressurization of an active magmatic system, J. Geophys. Res., 99, 4341-4354.

Mullineaux, D.R. and D.R. CRandell (1981): The eruptive history of Mount St. Helens, U.S. Geol. Surv. Prof. Pap., 1250, 3-15.

PARKER, R.L. and M.K. MCNUTT (1980): Statistics for the one-norm misfit measure, J. Geophys. Res., 85, 44294430 .

Reasenberg, P.A. and D. Oppenheimer (1985): Fortran computer programs for calculating and displaying earthquake fault-plane solutions, USGS Open-File Rep., 85-379, pp. 109.

SCANDONE, R. and S.D. MALONE (1985): Magma supply, magma discharge and readjustment of the feeding system of Mount St. Helens during 1980, J. Volcanol. Geotherm. Res., 23, 239-262.

SlejKo, D., G. Neri, I. Orozova, G. RENNER and M. WySS (1999): Stress field in Friuli (NE Italy) from fault plane solutions of activity following the 1976 main shock, Bull. Seismol. Soc. Am., 89 (4), 1037-1052.

Stanley, W.D., C. FinN and J.L. Plesha (1987): Tectonics and conductivity structures in the Southern Washington Cascades, J. Geophys. Res., 92, 1017910193.

WEAVER, C.S. and S.W. SMITH (1983): Regional tectonic and earthquake hazard implications of a crustal fault zone in Southwestern Washington, J. Geophys. Res., 88, 10371-10383.

Weaver, C.S., W.C. Grant and J.E. Shemeta (1987): Local crustal extension at Mount St. Helens, Washington, J. Geophys. Res., 92, 10170-10178.

WIEMER, S. and S. MCNUTT (1997): Variations in the frequency-magnitude distribution with depth in two volcanic areas: Mount St. Helens, Washington, and Mt. Spurr, Alaska, Geophys. Res. Lett., 24 (2), 189-192.

Williams, D.L., G. AbRams, C. Finn, D. Dzurisin, D. JOHNSON and R. DENLINGER (1987): Evidence from gravity data for an intrusive complex beneath Mount $\mathrm{St}$. Helens, J. Geophys. Res., 92, 10207-10222.

WYSS, M. and Z. LU (1995): Plate boundary segmentation by stress directions: Southern San Andreas Fault, California, Geophys. Res. Lett., 22 (5), 547-550.

WySS, M., B. LIANG, W.R. TANIGAWA and W. XIAOPING (1992): Comparison of orientations of stress and strain tensor based on fault plane solutions in Kaoiki, Hawaii, J. Geopliys. Res., 97, 4769-4790.

(received October 12, 1999; accepted July 19, 2000) 